\title{
Addition Error Patterns Among the Preschool Children
}

\section{Priyadarshini Muthukrishnan}

SEGi University, Malaysia, priyakrishnan.mail@gmail.com

\section{Mong Sze Kee}

SEGi University, Malaysia

\section{Gurnam Kaur Sidhu}

SEGi University, Malaysia

This study aimed to identify the different types of factual, conceptual and procedural errors among the six-years-old preschool children. The data were collected from 45 children from 3 kindergartens. The children responded to a Math worksheet which had 20 addition problems based on the early numeracy curriculum. The worksheet was validated by two experienced early childhood teachers. Both quantitative and qualitative methods were used to analyze the data. A total of 166 errors which occurred in the addition work of the participants were analyzed and categorized under 9 different types of addition errors. Further, the study revealed that $58 \%$ of the total errors were conceptual, $28 \%$ were factual and the remaining $14 \%$ were procedural errors in the addition operations. To gain deeper insights to the quantitative findings, seven children were identified and interviewed based on the nine errors. Findings from the interviews further corroborated the quantitative findings that, these children experienced misconception of mathematical knowledge, lack of procedural skills and memorizing facts which are inter related and precursors of each other. The findings of this study will facilitate teachers to adopt effective interventions and teaching methods to improve mathematical learning. The error analysis allows educators and content developers to understand the key development of young learners' knowledge and abilities in addition operations.

Keywords: error pattern analysis, early childhood, conceptual errors, procedural errors, factual errors, preschool children mathematics

\section{INTRODUCTION}

The early childhood educational practices consider learning as a hierarchical view that arithmetic follows counting skills. However, the nativist researchers claimed that infants have knowledge of simple arithmetic and children illustrated the arithmetic competence

Citation: Muthukrishnan, P., Kee, M. S., \& Sidhu, G. K. (2019). Addition Error Patterns Among the Preschool Children. International Journal of Instruction, 12(2), 115-132. https://doi.org/10.29333/iji.2019.1228a 
before their kindergarten (Sarama \& Clements, 2009). Many research findings on early numeracy acquisition have identified that kindergartners experience difficulty in understanding the abstract nature of Mathematics in a conventional classroom and teachers often experience challenges in developing the conceptual and procedural knowledge of the children. This has resulted in the occurrence of errors in the simple arithmetic computations among the preschool children. The consistency and the prevalence of the errors are to be carefully addressed by the teachers. The error analysis is a systemic analysis of the errors which acts as a diagnostic tool to understand the misconceptions and lack of mathematical skills among the children. Error analysis is a process of reviewing the errors with an objective to provide feedback and remediation instructions to improve the learning and performance. Ashlock (1998) concluded that teachers should understand their students learning and should identify the gaps and misconceptions in their mathematical learning. Error analysis requires mathematical and pedagogical knowledge of the teachers to analyze and interpret the errors. This helps teachers to broaden their mathematical cognition and to improve the instructions.

\section{LITERATURE REVIEW}

Radaz (1979) conceptualised the error analysis and many investigations in mathematical computation errors have contributed to the field of conceptual, procedural and factual knowledge on mathematics learning. Error analysis or error pattern analysis is the analysis of errors in learners' mathematical workings with the aim of identifying the common patterns and to find explanations for the causes of these errors (Herholdt and Sapire, 2014). The error analysis allows teachers to implement effective remediation (McGuire, 2013) and is an effective diagnostic tool to bridge the gap between the expected outcomes and the performance. Studies have identified that not all errors can be attributed to misconception or procedural knowledge. The errors which arise due to other factors other than knowledge and skills are termed as careless errors as reported by Yang, et. al. (2011) or slips according to Oliver (1996). These are otherwise called as non-systematic errors which are not caused due to conceptual or procedural knowledge unlike systematic errors. Yetkin (2003) reported that majority of the students' errors are often systematic and rule-based rather than non-systematic errors. Error analysis focusses on the systematic errors which occurred consistently and prevalent in students' work that reflects lack of knowledge and skills.

The debate between whether developing skills with symbols leads to conceptual understanding or whether the basic understanding precedes the skills has been a topic of investigation for many years and is referred to math war (Sowder, 1998). According to Hiebert and Lefevre (1986), conceptual knowledge is considered as a connected web of knowledge in which the discrete pieces of information or facts are linked and has prominent relationship that pervades the individual facts. Procedural knowledge is the familiarity with the operations, symbols, rules, procedures, syntax, steps or conventions which are sequential and predetermined to solve mathematical problems (Hiebert and Lefevre, 1986). Procedural knowledge allows the students to apply the predetermined steps to compute the correct answer. Based on the conception of conceptual and procedural knowledge as put forth by Hiebert and Lefevre (1986), Star (2005) argued 
that conceptual knowledge means connected concepts and it does not refer to knowledge of concepts or principles. It is primarily the quality of one's own knowledge of concepts, which is the richness of the connections inherent in such conceptual knowledge. The procedural knowledge is superficial and is not interconnected unlike conceptual knowledge. Madsen (1995) stressed on the need for conceptual knowledge. According to Madsen (1995) conceptual oriented instruction allows students to develop computation competence but students immersed in procedural oriented classroom will not facilitate students to develop conceptual knowledge. Numeracy in early childhood refers to the combinations of mathematical knowledge, ability to process, communicate and interpret numerical information in many different contexts (Clements \& Sarama, 2011). NCTM (2006) has proposed five content areas for the pre-schooler's numeracy: number and number operations, algebra, geometry, measurement and data analysis. The early numeracy primarily focusses on the knowledge and skills that are involved in the number operations and geometry. In Malaysia, the national preschool curriculum provided early Mathematics experience to the pre-schoolers (KPM, 2009). Based on the National Preschool Curriculum Standard, Malaysia (KSPK) the early numeracy skills required for six-years-old children are more advanced skills which included number concepts such as counting on, counting back, and skip counting, counting all and counting on strategy involved in computing addition and subtraction problems. Based on NCTM (2006), children of age six should master number operations involving two-digit numbers up to 100. Harun (2017) highlighted that KSPK (National Preschool curriculum, Malaysia) is abreast with the international standards of early numeracy.

Earlier studies have identified three distinct types of mathematical errors as factual, procedural, and conceptual errors in students' work which are due to students' lack of knowledge or misunderstanding (Fisher \& Frey, 2012; Riccomini, 2014). Factual errors occur due to lack of factual information. The most common factual errors are due to lack of vocabulary and digit identification. The most common reasons for procedural errors are lack of understanding of the steps involved in solving the problem. The conceptual errors arises due to lack of understanding of the various concepts that are fundamental to solve the problem and lack of understanding the relationship that interconnects the concepts that are fundamental to solve the problem (Brown \& Skow, 2016).

The relationship between facts, concepts and skills has been well explored and the research findings concluded that conceptual knowledge is essential for mathematics proficiency. The skills hierarchy view that arithmetic follows counting and simple work with numbers and therefore is beyond the children's grasp until their first grade. Frontera (1994) showed that, learning trajectory for adding and subtracting involves many conceptual and skill advancements. Based on the learning trajectory, the developmental progression for addition and subtraction which emphasis counting strategies shows that six-year-old children can demonstrate the counting strategies which includes counting-on (How much is five and two more?), counting-up-to (4+?=7) and part-whole relationship. Studies have identified that five to six-years-old children showed no relationship between their knowledge of commutativity, associativity and accuracy of solving arithmetic problems (Canobi et al., 2002). Knowledge of arithmetic 
concepts forms an organizing framework for storing arithmetic combinations (Canobi et al., 1998). The students with higher conceptual knowledge use sophisticated strategies and retrieve combinations accurately. Therefore, the term 'fact' is not preferred and knowing the arithmetic combination well means far more than knowing a simple, isolated 'fact' (Sarama \& Clements, 2009). Riccomini (2005) have identified that teachers are often not well equipped to understand the need for intervention and design appropriate interventions that mediates their arithmetic learning. Therefore, error analysis approach will provide ample opportunity for the teachers to identify and remediate the learning process. Failing to address the causes for the errors are potential threat for developing early numeracy skills and children face multifaced difficulties in learning Mathematics. Error analysis fills the gap between the expected and the actual outcomes and brings the teacher and learner to reflect on their practices. The literature review has identified that no earlier research has been attempted in investigation error pattern among the early learners. The current research will shed new insights in the field of error analysis of addition operations and the findings will have major implications in the teaching- learning process. The current study aims on the following research questions.

1. What are the error patterns in addition operations that are common among preschool children?

2. What are the underlying misconceptions among preschool children that cause factual, conceptual and procedural errors in addition operations?

\section{METHOD}

The present study employed mixed research method to address the research questions. To identify the error pattern, data were collected using quantitative method by conducting a Math test. Qualitative method was used to probe on the misconceptions that were the root causes for the consistent errors. Children were interviewed and allowed to demonstrate their understanding in solving the addition problems. RittleJohnson, Siegler, \& Alibali, (2001) and Riccomini (2014) have identified that often conceptual and procedural knowledge overlaps and it is difficult to distinguish conceptual errors from procedural errors. Therefore, in the current research to corroborate the findings of quantitative research, interviews were conducted to confirm the findings.

\section{Participants}

The target population was six-years-old children from private preschools at Kota Damansara in Malaysia. A representative sample of 45 children from three private urban preschools participated in this study. The preschools selected for the study followed the common Mathematics preschool curriculum and adopts activity-based teaching in Mathematics classroom. Further, the sample selected for the study ensured that the children with mixed mathematical ability were part of the study. This was given due consideration, to ensure that the errors that occurred are common across children with all levels of mathematical skills and to prevent skewed data for the analysis. The selected samples were representative of mixed ability group and the children were 
selected based on their previous Math test scores. 15 children from each group of high $(33.3 \%)$, average $(33.3 \%)$ and low achievers $(33.3 \%)$ were considered for the study. The data were collected almost towards the end of the kindergarten years and the children were to be transitioned to primary schools in the following academic year. For the interview, seven children (refereed as $\mathrm{C} 1$ to $\mathrm{C} 7$ in the study) were selected to investigate the misconceptions that allowed them to provide erroneous results.

\section{Research Instruments}

The research instruments used for collecting data from the children were Math worksheet and interview questions. The Math worksheet was carefully constructed based on the learning objectives of the Mathematics preschool curriculum. The preschool Math curriculum aims to achieve counting on skills, recall of addition number facts, number facts involving zero, the commutative property of additions, adding tens and units which involves with and without regrouping processes and adding more than two addends. The researcher constructed the Math worksheet of 20 addition problems in which the addends were presented in horizontal form as an equation rather than the conventional vertical form of addition. This was aimed to identify the children in understanding of place value and position of numbers while computing addition. The content validity of the research instrument was determined by a panel of experts. Three well experienced kindergarten teachers and two lecturers from early childhood education verified the test items by aligning the items to the learning objectives of the addition skills. The children were allowed to complete their test at their own pace and sufficient time was provided to them. To examine and interpret the conceptual, factual and procedural knowledge and competence of the children in addition operations, seven children were interviewed to demonstrate their understanding and the procedure they followed in computing the sum.

\section{Data Collection}

The children were briefed about the Math worksheet and their willingness to take part in the study was given due consideration. As the entire class was not considered as the sample of the study, the children who were chosen for the study were separated from the rest of the class and the test was conducted to them in a conducive environment. The children completed the worksheet with an average of 15 minutes.

To answer the second research question, data were collected through interview from seven children. The interview sessions were conversational in nature and attempted to allow the children to demonstrate how they approached solving a particular problem and discuss the reasons why they approached in that certain way. The interview protocol primarily included three basic questions to identify the misconceptions that directed them to computational errors and probing questions were used for deeper understanding of the underlying misconceptions. The interview sessions were recorded and transcribed. The interview questions were:

1. Is it an easy problem to solve?

2. Now, can you please do it again and explain to me as you are doing it?

3. Are you sure your answer is correct? 
Further, before the start of the interview the children were not informed about their overall score or the wrong answers. Throughout the research, the anonymity of the children participated in the research were maintained.

\section{Data analysis}

The children completed the worksheet and the responses were corrected. The data were analyzed inductively to identify the underlying common patterns among the errors. The current research considered systematic errors. According to Howell, Fox, \& Morehead (1993) and Radatz (1979) an error pattern should be considered on account of at least three to five errors on a specific type of problem. The computational error patterns that were identified in the earlier studies were taken in to consideration to infer the error pattern in the present study. This was followed by deductive approach to analyze the data in which count and the frequency for each of the identified errors were computed. The error patterns identified in the current study were further categorized under conceptual or procedural or factual errors. Furthermore, interviews were conducted to confirm the identified error patterns.

The current research adapted the seven steps in investigating mathematical error pattern as suggested by Howell et. al., (1993). The first step involves collection of sufficient number of computation data from the selected samples. In the second step the children are allowed to talk aloud while solving the problem and the teacher or the researcher should avoid providing cues in solving the problem. This is followed by recording all the verbal and written data. In the fourth step, the researcher will analyze the data and identify common patterns that are consistent among the sample. The researcher should consider identifying the error patterns that are exceptions that indicate partial understanding of procedure or concept. In the sixth step, the researcher will name the error pattern based on the nature of the errors. In the final step, the students are interviewed to confirm the error patterns identified.

\section{FINDINGS}

To answer the first research question, the scored worksheets were analysed for the errors. Item wise errors were calculated to find out the percentage of errors. This was followed by grouping and categorising the errors based on the common patterns that existed among the errors. Further, analysis of the errors allowed the researcher to categorise the errors into conceptual or factual or procedural errors.

\section{Item-wise analysis of errors}


Table 1

Descriptive of item-wise errors in addition $(\mathrm{n}=45)$

\begin{tabular}{llll}
\hline Item no. & Item & Addition errors N $(\%)$ & Percentage of errors \\
\hline 14 & $76+17=93$ & $16(35.5 \%)$ & $9.64 \%$ \\
\hline 15 & $46+36=82$ & $15(33.3 \%)$ & $9.04 \%$ \\
\hline 16 & $19+30=49$ & $15(33.3 \%)$ & $9.04 \%$ \\
\hline 18 & $38+44=82$ & $14(31.1 \%)$ & $8.43 \%$ \\
\hline 20 & $8+7+5=20$ & $14(31.1 \%)$ & $8.43 \%$ \\
\hline 6 & $6+78=84$ & $13(28.8 \%)$ & $7.83 \%$ \\
\hline 17 & $25+25=50$ & $12(26.6 \%)$ & $7.22 \%$ \\
\hline 5 & $76+6=82$ & $11(24.4 \%)$ & $6.62 \%$ \\
\hline 8 & $40+6=46$ & $9(20.0 \%)$ & $5.42 \%$ \\
\hline 11 & $5+59=64$ & $8(17.8 \%)$ & $4.81 \%$ \\
\hline 19 & $8+43=51$ & $8(17.8 \%)$ & $4.81 \%$ \\
\hline 7 & $2+3+4=9$ & $7(15.5 \%)$ & $4.21 \%$ \\
\hline 12 & $2+89=91$ & $6(13.3 \%)$ & $3.61 \%$ \\
\hline 4 & $12+4=16$ & $5(11.1 \%)$ & $3.0 \%$ \\
\hline 13 & $65+7=72$ & $3(6.7 \%)$ & $1.8 \%$ \\
\hline 1 & $25+3=28$ & $3(6.7 \%)$ & $1.8 \%$ \\
\hline 2 & $4+4=8$ & $2(4.4 \%)$ & $1.2 \%$ \\
\hline 10 & $3+7=10$ & $2(4.4 \%)$ & $1.2 \%$ \\
\hline 3 & $65+1=66$ & $2(4.4 \%)$ & $1.2 \%$ \\
\hline Total addition errors & $1(2.2 \%)$ & $0.6 \%$ \\
\hline
\end{tabular}

The Table 1 displays the item-wise percentage of the errors in the addition operations among the preschool children. The results identified a total of 166 errors for the 20items test. Nine children scored the full marks in the math test. Table 1 shows that children showed better performance in adding small numbers compared to large numbers. The research identified that there were nine types of error patterns which were further categorized under factual, conceptual and procedural errors.

The results concluded that there were three types of factual, four types of conceptual and two types of procedural errors. Table 2 shows the type of errors and the descriptive of each error that are common among the preschool children. The research findings unveiled the fact that the most prevalent errors were the conceptual errors and these errors accounted for $58 \%$ of the total errors, followed by $28 \%$ of the factual errors and the least were the procedural errors with $14 \%$. 
Table 2

Descriptive of the common addition errors among the pre-school children

\begin{tabular}{|c|c|c|c|}
\hline Mathematical Errors & Addition Error Types & Frequency $(\%)$ & $\begin{array}{l}\text { Percentage of } \\
\text { errors }\end{array}$ \\
\hline \multirow{3}{*}{ Factual errors } & Failed to recall addition facts & $27(16.26 \%)$ & \multirow{3}{*}{$28 \%$} \\
\hline & Incorrect sums when zero is an addend & $10(6.02 \%)$ & \\
\hline & Incorrect sums when adding more than two digits & $10(6.02 \%)$ & \\
\hline \multirow{4}{*}{ Conceptual errors } & Sums are recorded without regrouping & $30(18.07 \%)$ & \multirow{4}{*}{$58 \%$} \\
\hline & Sums are recorded regardless of place value & $23(13.85 \%)$ & \\
\hline & Skipped regrouping when needed & $35(21.08 \%)$ & \\
\hline & Placing extra tens before regrouping & $8(4.8 \%)$ & \\
\hline \multirow{3}{*}{ Procedural errors } & Digits of addends are summed all together & $10(6.02 \%)$ & \multirow{2}{*}{$14 \%$} \\
\hline & Incomplete calculation & $13(7.83 \%)$ & \\
\hline & Total errors & $166(100 \%)$ & $100 \%$ \\
\hline
\end{tabular}

\section{Factual error: Failed to recall addition facts}

This type of error pattern revealed that memory deficit is the major cause for the error. The children were familiar with the procedure. However, they had not mastered the basic addition facts. Probing further, these types of errors also indicate carelessness and lack of attention in the task. The Figure 1 displays this error type. This error pattern was found across all the items and accounted for $28 \%$ of the total errors. When the children $\mathrm{C} 1, \mathrm{C} 2$ and $\mathrm{C} 5$ were interviewed to demonstrate their understandings in solving the item $4(5+7=$ ?), their responses clearly highlighted memory deficit and lack of attention. The interview excerpts are as below

C1: "I forgot that"

C2: “mmm...I don't know “

C5: "I was playful, that's why I was wrong"

The children $\mathrm{C} 1$ and $\mathrm{C} 2$ were asked to add 5 and 7. They tried to solve using mental arithmetic and were able to recall the addition fact $7+5=12$ with relative ease compared to $5+7=12$. This confirmed that children struggled to apply the commutative property of addition. They were able to switch between $5+7$ and $7+5$ easily when counted using finger method. C5 used counting-on-from-larger number method to solve item 14 (76+ $17=)$ and was able to count on from 7 till 6 more and reported the correct answer 13 . The responses clearly showed lack of familiarity of addition facts, lack of comprehension of number facts and counting errors (Lestiana, et. al, 2016). These errors are called as slips, which are caused due to lapse of memory or impulsive behavior of the children. According to Fisher \& Frey (2012) these errors are caused due to fatigue or distraction.

The Figure 1 displays this error type. 

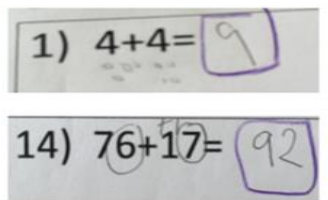

Figure 1

Failed to recall addition facts

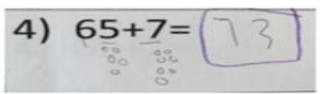

11) $8+43=$

\section{Factual error: Incorrect sums when zero is an addend}

The item no. 3, 9 and 16 were used to analyze the children's understandings in computing addition that involves zero as a digit in the addend. The very low percentage of error in item no. $3(1 \%)$ indicated that the children were able to solve addition that involves adding zero to a single digit. However, the percentage of errors in item no. 9 ( 9 $\%)$ and item no. $16(15 \%)$ showed that children experienced lack of understanding while adding two digits addends that have zero. Wellen and Miller (1986) identified that handling mathematical operations requires the understanding of the number zero. The interview with the children $\mathrm{C} 4, \mathrm{C} 5$ and $\mathrm{C} 7$ demonstrated that the children used finger counting method to calculate the sum and they have completely ignored the digit at the 'tenth' place. All the three children presented correct answer for item $3(9+0=9)$ and item $9(40+9=49)$ which is relatively easier compared to item $16(19+30=49) . \quad C 4$ and C5 were able to provide the correct answer for $30+9$ as 39 . When the children were asked for the sum of $19+30$ they faced difficulty. The interview results revealed that children had difficulty in understanding the concept of place value when applied to zero as a digit in large numbers. These children were able to identify the place values of the natural numbers which does not involve zero. They attempted to solve the item 16 using count-all strategies or simple recall of addition facts and completely ignored the digit ' 1 ' in number 19. Their response when asked to demonstrate why they excluded "1" from 19 while adding the 2 numbers 19 and 30, is shown in below excerpts.

C4: "I add 30 and 9 and put it down there 39. But I don't know to add with big numbers"

C5:"I add 9+ 0 first and then...I am not sure of the next step"

C7:" I see here 30 and 9 here... so I put $30+9$ is 39 .and...mmm..ya.. I missed this 1 "

Wellen and Miller (1986) proposed that handling zero is difficult for preschoolers and they could understand the concept of zero only when they know that zero is the smallest number. Most of the preschoolers believe that ' 1 ' is the smallest number which hinders them with the mathematical operations.

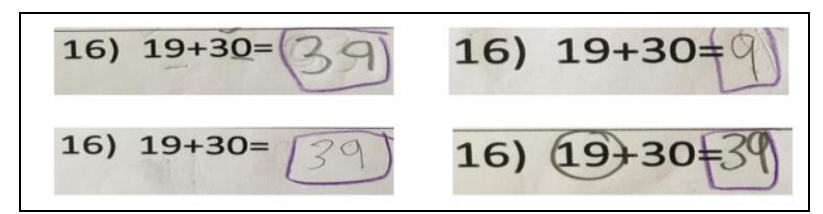

Figure 2

Incorrect sums when zero is an addend 


\section{Factual error: Incorrect sums when adding more than two digits}

The item no. 19 and 20 investigated the children's' addition computational skills that involved adding three numbers. The percentage of errors in item no. 19 (7\%) is less compared to the error in item no. 20 (14\%). The findings confirmed that children's addition skills in adding small numbers were better compared to the addition of numbers that involved carry forward and regrouping process. The interview clearly identified that children showed lack of familiarity to this type of problems. Also, they failed to demonstrate the associative property of addition.

Three children $\mathrm{C} 3, \mathrm{C} 5$ and $\mathrm{C} 7$ were interviewed to identify their misconception in solving the item $20(8+7+5=20)$. C3 solved the item 19 and made an error in solving item 20 . The children added the numbers from left to right and in doing so, they were able to say $7+5$ is 12 . Proceeding further they were not clear of adding 12 with 8 .

When the children were asked to use number line to solve the problem, they demonstrated clear understandings and reported the correct answer. Further, the children were able to solve the addition when the sum is less than 10 .

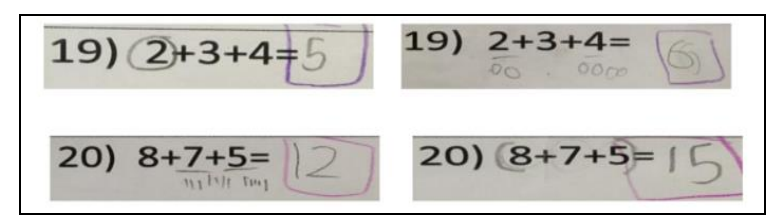

Figure 3

Incorrect sums when adding more than two digits

\section{Conceptual error: Sums are recorded without regrouping}

The findings confirmed that $18.07 \%$ of the total errors were due to the error pattern names as 'sums are recorded without regrouping'. The children recorded the sums of the ones and tens place without regrouping. This type of error was due to adding columns, with no intention to place value or regrouping. The lack of conceptual knowledge has preceded the procedural skills and the sums were recorded incorrectly. The present findings agreed with similar findings of Engelhardt (1997). Furthermore, these errors are considered as systematic errors When the children $\mathrm{C} 1, \mathrm{C} 5$ and $\mathrm{C} 7$ were interviewed to solve the item $15(46+36=82)$, they expressed that they viewed the numbers in the unit and the tenth place of the two addends as discrete and different entities and carried out the addition operation. The following are the responses provided by the children when asked to reason out why they followed in that certain way to answer item 15

C1: "I know to solve addition...like ...small numbers only"

C5: "These numbers are big and I cannot use finger counting. So, I am confused"

C7: "I am not sure of the carry forward and place values" 


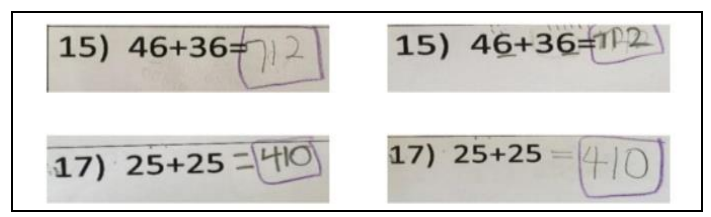

Figure 4

Sums are recorded without regrouping

\section{Conceptual error: Sums are recorded regardless of place value}

The children's conceptual knowledge in recognizing the place value had resulted in incorrect sums and this was accounted for $13.85 \%$ of the total errors. The interview with the children indicated that the children were able to provide correct answers when the addition problem was presented in vertical form. In the vertical form of addition, the digits were already placed based on the place value, and the children found it comfortable to solve the problem. However, when the same addition problems were presented in the horizontal form, the children showed misunderstanding of the place value and they were confused to align the numbers based on the correct place value. Pincus (1975) refereed this error as poor alignment of digits in columns, when the addition problem is presented in vertical form. When the children C5, C6 and C7 were interviewed, their responses clearly depicted their misconception of place value and the importance of place value in solving addition. C5, C6 and C7 were asked to demonstrate the procedure they followed in solving item $18(38+44=82)$, item $11(8+43=51)$ and item $8(5+59=64)$ respectively. Their responses as below

C5: "I first add 8 and 4. so,...9,10,11,12,,,I put here 12 and then I add 3 and 4 and put here 7"

C6: "I think I first added 8 and 4. Is it correct miss? ...then I just bring this 3 here.

C6 was not certain about his answer and was expecting affirmations from the teacher.

C7: "this 5 plus this 5 is 10 and then this 9 comes here. There is no partner to add for this 9"

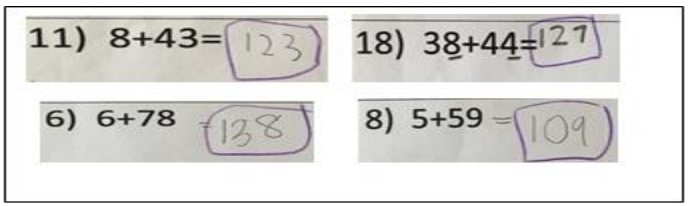

Figure 5

Sums are recorded regardless of place value

\section{Conceptual error: Skipped regrouping when needed}

Results showed that $21.08 \%$ of the errors were due to skipped regrouping when needed. This error pattern results revealed that children had better knowledge of the place value and addition facts, but they have completely ignored the concept of carry forward when needed. Most of the errors of this type showed that the recorded sum was lesser than one 
of the addends as represented in the Figure 6 below. When children were asked to demonstrate their understanding, they had difficulty in understanding the concept of carry forward to the tenth place. Their conceptual knowledge in regrouping have resulted in the incorrect procedure in solving the problems. Robert (1968) named this type of error as failing to add the carried number. Bruckner (1930) identified similar error pattern in multiplication operation. C1 and C5 were interviewed to gather insights into their understandings of place value. $\mathrm{C} 1$ was asked to solve item $5(76+6=82)$ and C5 solved item $8(5+59=64)$ and explained aloud as they proceeded to solve the problem.

C1: "I add 6 and 6 . I get 12. So I put 2 here. But I don't know what I have to do with this 1 . And I bring this 7 here"

C5 : "first I add 9 and 5 and I got...mmm...10,11,12,13, 14,,,so I write 4 in my answer and then....this 5 comes here"

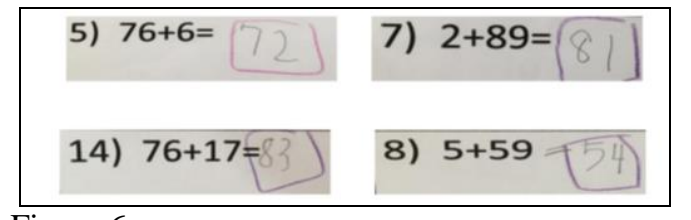

Figure 6

Skipped regrouping when needed

\section{Conceptual error: Placing extra tens before regrouping}

This error pattern occurred when children placed extra tens in the tenth place and recorded their answer and accounted for 4.8\% of the total error. This type of error pattern is contradictory to the conceptual error pattern 3, skipped regrouping when required. When interviewed the children presumed that addition which involves larger numbers were certain to have carry forward and they placed extra tens $(+1)$ before even starting to add the numbers. They had high reliance on the rules of placing tens when they realized that the problem needed regrouping process. This type of error in which the answers are recorded with extra tens is shown in Figure 7 as below. The researcher suspected that this error might be due to factual error type 1. However, interview revealed that the causes of this error are due to lack of conceptual understandings. The extracts in Fig 7 give evidences that children have mastered unit counting and the concept of place value. But their misconception lies in the assumptions that they hold about addition of large numbers.

$\mathrm{C} 2$ demonstrated solving item $6(6+78=84)$ as follows

"I see the numbers are all big. So, I put here 1 on top of 7. I add 8 and 6 and I get 14. I put 4 and carry forward 1 here, So, I add 7,1 and 1...it is 9 .

C7 responded to item 16 as

"I write 1 here and then I add $9 \ldots$ add with 0 is 9 only. I write 9 . Ok. I add 3 and 1 and $1 \ldots$ it is $5 "$. 


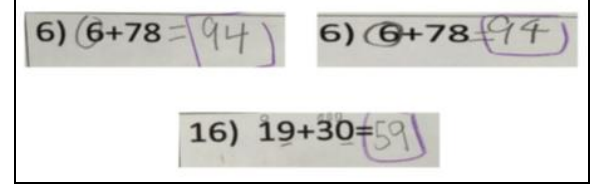

Figure 7

Placing extra tens before regrouping

\section{Procedural error: Digits of addends are summed all}

The fact that digits of addends were summed all together was due to lack of procedural skill to solve the problem. The children interview revealed that they have mastered basic addition facts but they lack the recognition of place value. When the children were asked to demonstrate their understanding, they had split the two-digit numbers into two separate single digit numbers and had carried out the addition operation. This error pattern is shown in Figure 8. This error pattern agreed with Mercer \& Mercer (1998) and Graeber \& Wallace (1997). Graber \& Wallace (1997) called this error as digits of addends are summed, disregarding place value. $\mathrm{C} 1$ and $\mathrm{C} 5$ explanation revealed that they considered each number as a discrete entity with no regard of place value. However, their comprehension of number facts was considerably good.

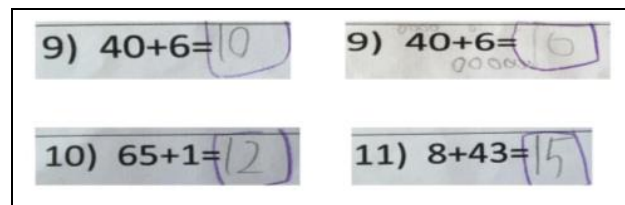

Figure 8

Digits of addends are summed all

\section{Procedural error: Incomplete calculation}

The results indicated that $7.83 \%$ of the total error was due to incomplete calculation. There were variety of responses for this type of error and few are depicted in the figure 9 below. The incomplete calculation showed that the children had not mastered the addition procedure or algorithm to complete the problems. The children had good understanding of addition number facts and the concept of place value, but they did not complete the computation as they were uncertain about the next step to be continued on. The interview results showed that the children were anxious to present only the right answer and they were unable to proceed further to complete the sum. Hudson \& Miller (2006) confirmed similar error pattern.

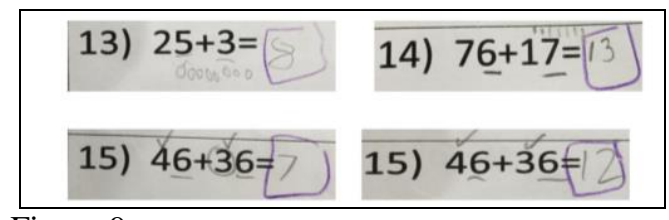

Figure 9

Incomplete calculation 


\section{DISCUSSION AND CONCLUSION}

The current research concluded that majority of the errors employed by the children in addition operation were the conceptual errors which indicated the need for appropriate intervention to improve conceptual learning. Wijaya (2017) identified similar findings that the fourth graders showed low conceptual knowledge in solving fractions. This confirmed that the most consistent errors among children were due to lack of conceptual knowledge and competency. However, the current study finding contradicts with Riccomini (2014) in which procedural errors were the most common type of errors. Further, the interview findings confirmed that children were not familiar with terms used in the addition operation. Pesek \& Kirschner (2000) argued that procedural knowledge plays a secondary and supportive role to conceptual knowledge. Furthermore, conceptual knowledge and language proficiency of the children are crucial in solving problems. Vygotsky (1978) argued that language is a powerful mediation of learning. Several researchers (Riccomini, 2005; Yang et al., 2011, Herhodt \& Sapire, 2014) concluded that error analysis is an important skill needed for Mathematics teachers teaching non-native speakers of English. Earlier research findings have proved that language has a significant influence on the arithmetic understanding especially on the place values (Ross, 1986).

The current study, identified difficulties among the children in understanding the term 'place value', 'regrouping' and 'carry forward'. The mathematical terms used in the classroom should be taken into serious consideration by the teachers. Active learning approaches to understand the basic concepts should be the teaching methodology to ease the development of conceptual knowledge. Warren (2003) reported that children's' limited understanding of the mathematical terms leads to poor arithmetic performance. Children fail to construct meaning of the mathematical meaning in the realm of numbers if they fail to understand the terms. Ho \& Fuson (1998) identified that a Chinese fiveyear-old with good verbal counting understood tens-and-ones in a task in which a single digit number was added to 10, but English- speaking children did not. Further, the findings reported that teaching that allowed children to develop conceptual knowledge allowed children to perform high in Mathematics. The current study identified that $28 \%$ of the total errors were factual errors. The findings revealed that lack of attention, lack of comprehension of number facts and difficulty to recall basic addition facts were the causes for factual errors. Rote memory learning in the addition of small numbers have facilitated the children to compute the addition with speed and accuracy. Further, children who were familiar with addition facts were able to verify their answers and were confident of their work. This confirmed that factual knowledge eases the mathematical learning and it improves their thinking skills and involvement in learning. The children addition working indicated that most common strategy to solve the problem was by representing numbers using manipulatives or drawings of little objects (circles/strokes etc..) and they considered counting on, counting all or counting by ten counting strategies to compute the sum. This confirmed that causes for the errors were due to mechanical use of unit counting with little or no understanding of the place value. Further, the results showed that children were able to perform well in adding small numbers compared to large numbers. The findings of this research are aligned with 
Levine et al., (1992) which concluded that children do not solve larger number problems without the support of concrete objects until five and half years of age. The findings of the study agreed with Jung et. al (2013) which confirmed that teaching number relationship is important in the preschool mathematical instructions to improve their mathematical performance. The interview with children who made error in regrouping process displayed that they had little understanding of the regrouping process. This concluded that learners should be provided ample opportunities to explore their understanding of the abstract concepts before being taught the basic terms and rules to solve the computational problems. Idris (2011) identified that the popularity of the printed materials showed that children learn mathematics in symbolic settings rather than experiential approach. In the present study, the procedural error accounted for $14 \%$ of the total errors. The interview results showed that children had little understanding of procedure to carry out the addition. The interview with the children further confirmed that teachers' individual attention to the child and creating opportunities to enumerate and reflect on the errors contributed to great deal of understanding of their computational operation.

This study concluded that conceptual oriented instructions are the need of the hour to improve early numeracy skills. The study recommends that conceptual oriented teaching practices are important for the overall performance in Mathematics. The spread of errors in the addition operation confirmed that the children were not conceptually matured to achieve the objectives of the curriculum. However, the curriculum and instructions direct children to master addition operation that are far ahead of their conceptual knowledge and skills. This urges the teachers and early childhood educators to design and implement curriculum which facilitates learning abstract concepts through manipulatives, mathematical models and concrete objects. The interview discussion with the children who demonstrated their approach in solving the problem confirmed that metacognitive approaches, self- assessment and reflection on the errors are insightful for the learners to create better conceptual knowledge. Opportunities to reflect and selfassess their math work should be created in the classroom. Dialogic discussion between the teacher and student will create deeper conceptual understanding among children. Further, error analysis should be used by the teachers as a diagnostic tool to investigate the learner's understanding and to improve classroom instructions.

\section{REFERENCES}

Ashlock, R. B. (1998). Error pattern in computation (7th ed.)., New Jersey, NJ: Prentice Hall.

Brown J., Skow K. (2016). Mathematics: Identifying and addressing student errors. Retrieved from http://iris.peabody.vanderbilt. edu/case_studies/ics_matherr.pdf

Brueckner, L. J. (1930). Diagnostic and remedial teaching in arithmetic. Chicago: John C. Winston.

Canobi, K. H., Reeve, R. A., \& Pattison, P. E. (1998). The role of conceptual understanding in children's addition problem solving. Developmental Psychology, 34, 882-891. 
Canobi, K., Reeve, R., \& Pattison, P. (2002). Young children's understanding of addition concepts. Educational Psychology, 22(5), 513-532.

Clements, D. H., \& Sarama, J. (2009). Learning and teaching early math: the learning trajectories approach. New York: Routledge.

Clements, D. H., \& Sarama, J. (2011). Early Childhood Mathematics education Research: learning Trajectories for Young Children. New York, NY: Routledge.

Engelhardt, J. M. (1977). Analysis of children's computational errors: A qualitative approach. British Journal of Educational Psychology, 47, 149-154. doi: 10.1111/j.2044-8279. 1977.tb02340.x

Fisher, D., \& Frey, N. (2012). Making time for feedback. Feedback for Learning, 70, $42-46$.

Frontera, M. (1994). On the initial learning of mathematics: Does schooling really help? In J. E. H. Van Luit (Ed.), Research on learning and instruction of mathematics in kindergarten and primary school (pp. 42-59). Doetinchem, the Netherlands: Graviant

Graeber, A. O., \& Wallace, L. (1977). Identification of systematic errors: final report. Philadelphia: Research for Better Schools, Inc. (ERIC Document Reproduction Service No. ED 139662)

Harun. J., Ghazali. M., Hamid. A. B. Z., \& Nasir. M. I. M. (2017). Content of Early Numeracy in the Malaysian Preschools. International Journal of Academic Research in Business and Social Sciences, 7(2). DOI: 10.6007/IJARBSS/v7-i2/2657

Herholdt. R., \& Sapire. I. (2014). An error analysis in the early grades mathematics: A learning opportunity. South African Journal of Childhood Education, 4, 42-60.

Hiebert, J., \& Lefevre, P. (1986). Conceptual and procedural knowledge in mathematics: An introductory analysis. In J. Hiebert (Ed.), Conceptual and procedural knowledge: The case of mathematics (pp. 1-27). Hillsdale, NJ: Erlbaum

Ho, C. S-H., \& Fuson, K. C. (1998). Children's knowledge of teen quantities as tens and ones: Comparisons of Chinese, British, and American kindergartners. Journal of Educational Psychology, 90, 1536-1544

Howell, K. W., Fox, S., \& Morehead, M. K. (1993). Curriculum-based evaluation: Teaching and decision-making. Pacific Grove, CA: Brooks/Cole.

Howell, K.W., Fox, S.L., \& Morehead, M.K. (1993). Curriculum-based evaluation: Teaching and decision- making (2nd ed,). Pacific Grove, CA: Brooke/Cole.

Hudson, P. \& Miller, S. (2006). Designing and Implementing Mathematics Instruction for Students with Diverse learning Need. Boston: Allyn \& Bacon.

Idris, S. \& Latha Maheswari Narayanan (2011). Error patterns in addition and subtraction for fractions among form two students. Journal of Mathematics Education, 4(2), 35-54. 
Kementerian Pelajaran Malaysia. (2009). Dokumen standard prasekolah: Kurikulum Standard Prasekolah Kebangsaan. Kuala Lumpur: Bahagian Pembangunan Kurikulum, Kementerian Pelajaran Malaysia

Jung. M.; Smith. T. \& Wallace. S. (2013). The Effectiveness of Teaching Number Relationships in Preschool. International Journal of Instruction, 6(1), 165- 178.

Lestiana, H.T., Sri Rejeki.S \& Setyawan. F. (2016). Identifying Students' Errors on Fractions. Journal of Research and Advances in Mathematics Education. 1, 131-139.

Levine, S.C., Jordan, N.C., \& Huttenlocher, J. (1992). Development of calculation abilities in young children. Journal of Experimental Child Psychology, 53, 72- 103.

Madsen, L. A. (1995). Does conceptually oriented instruction enhance computational competence? Focus on Learning Problems in Mathematics, 17(4), $42-53$.

McGuire, P. 2013. Using online error analysis items to support pre-service teachers' pedagogical content knowledge in mathematics. Retrieved from http://www. citejournal.org/vol13/iss3/mathematics/article1.cfm

Mercer, C., \& Mercer, A. (1998). Teaching students with learning disabilities (5th ed.). Columbus, OH: Merrill.

National Council of Teachers of Mathematics. (2006). Curriculum Focal Points for PreK-Grade 8 Mathematics: A Quest for Coherence. Library of Congress Cataloging NCTM. United states of America: The National Council of Teachers of Mathematics, Inc. $\quad$ Retrieved from http://search.ebscohost.com/login.aspx?direct=true\&db=aph\&AN=23869416\&amp;lang $=$ es\&site=ehost-live

Olivier, A. 1996. Handling pupils' misconceptions. Pythagoras, 21,10-19.

Pesek, D. D., \& Kirschner, D. (2000). Interference of instrumental instruction in subsequent relational learning. Journal for Research in Mathematics Education, 31, 524-540.

Pincus, M., Coonan, M., Glasser, H., Levy, L., Morgenstein, F., Shapiro, H. (1975). If you don't know how children think, how can you help them? The Arithmetic Teacher, $22,580-585$

Radatz, H. (1979). Error analysis in mathematics education. Journal for Research in Mathematics Education, 10(3), 163-172.

Riccomini, P. J. (2005). Identification and Remediation of Systematic Error Patterns in Subtraction. Learning Disability Quarterly, 28/3, 233-242. doi:10.2307/1593661

Riccomini, P. J. (2014). Identifying and using error patterns to inform instruction for students struggling in mathematics. Webinar series, Region 14 State Support Team.

Rittle-Johnson, B., Siegler, R. S., \& Alibali, M. W. (2001). Developing conceptual understanding and procedural skill in mathematics: An iterative process. Journal of Educational Psychology, 93, 346-362. 
Roberts, G. H. (1968). The failure strategies of third grade arithmetic pupils. The Arithmetic Teacher, 15, 442-446.

Ross, S. (1986). The development of children's place-value numeration concepts in grades two through five. Paper presented at the Annual Meeting of the American Educational Research Association, San Francisco, CA.

Sowder, J. T. (1998). What are the "math wars" in Californiall about? Reasons and perspectives. Retrieved from https://faculty.tarleton.edu/brawner/coursefiles/579/Math\%20Wars\%20in\%20California .pdf

Star, J. R. (2005). Reconceptualizing Procedural Knowledge. Journal for Research in Mathematics Education, 36(5). 404- 411.

Vygotsky, L. S. (1978). Mind in Society: The Development of Higher Psychological Processes. Cambridge, MA: Harvard University Press.

Warren, E., \& Cooper, T. (2003). Introducing equivalence and inequivalence in Year 2. Australian Primary Mathematics Classroom, 8(10), 4-9.

Wellman, H. M., \& Miller, K. F. (1986). Thinking about nothing: Development of concepts of zero. British Journal of Developmental Psychology, 4(1), 31-42.

Wijaya, A. (2017). The Relationships between Indonesian Fourth Graders' Difficulties in Fractions and the Opportunity to Learn Fractions: A Snapshot of TIMSS Results. International Journal of Instruction, 10(4), 221-236. doi: 10.12973/iji.2017.10413a

Yang, C. W., Sherman, H., \& Murdick, N. (2011). Error Pattern Analysis of Elementary School-Aged Students with Limited English Proficiency. Investigations in Mathematics Learning, 4(1), 50-67. doi:10.1080/24727466.2011.11790309

Yetkin, E. (2003). Students' difficulties in learning elementary mathematics. Retrieved from http://www.tpdweb.umi.com/tpweb 